\title{
Sorovares de Salmonella isolados de carcaças e cortes de frango obtidos na indústria e no comércio em Jaboticabal, Estado de São Paulo, em 1996
}

\section{Serovars of Salmonella isolated from carcass and cuts of chicken ob- tained from industry and commerce, in Jaboticabal, State of São Paulo, during 1996}

\author{
Francisca Neide Costa', Oswaldo Durival Rossi Junior², Antonio Nader Filho², Ana Terezinha Tavechio ${ }^{3}$
}

\section{Resumo}

Com o objetivo de verificar a ocorrência de Salmonella sp. e identificar os sorovares, foram analisadas 105 amostras de carcaças de frango colhidas em abatedouros, sendo 60 provenientes de abatedouro com controle higiênico-sanitário permanente e 45 de abatedouro sem controle e, ainda, 45 amostras de cortes comerciais (peito, coxa e asa) colhidas no mercado varejista de Jaboticabal, Estado de São Paulo. Nas amostras de carcaças obtidas no abatedouro com controle, a positividade para salmonela foi de $8,3 \%$ e nas amostras do abatedouro sem controle foi de $13,3 \%$. Nos cortes, o percentual médio de contaminação por salmonelas foi de $35 \%$, sendo que $46,6 \%$ das amostras eram de asas, $40 \%$ de peitos e $20 \%$ de coxas. Foram identificados dez diferentes sorovares: $S$. Senftenberg, S. Schwarzengrund, S. Minnesota, S. I 4, 5,12: r:-, S. Heidelberg, $S$. Anatum, $S$. Hadar, S. Enteritidis, $S$. Agona e $S . \mid 1$ 1 4, 5, 12: r:-; o sorovar de maior freqüência foi o de $S$. Enteritidis. É necessária a adoção de rigorosas medidas higiênico-sanitárias ao nível de produção, abatedouro e comércio, para reduzir o percentual de carcaças e cortes de frango contaminados por salmonelas $e$, conseqüentemente, os riscos que estes representam para a Saúde Pública.

Palavras chave: Salmonella sp.; carne de frango; abatedouro; comércio

\section{Introdução}

Atualmente, os produtos cárneos, principalmente as carnes de frango, parecem ser os principais veiculadores das salmonelas, sendo as diferentes fases do abate $e$ processamento consideradas como os mais importantes pontos de disseminação da bactéria para as carcaças.
São vários os relatos de ocorrência de salmonelas em carcaças de frango provenientes de abatedouros. Estudos em carcaças de frango obtidas em abatedouros realizados por Cunha Neto et al. (1982) na cidade de Goiânia, por Machado et al. (1994) no Estado de Santa Catarina e por Tadesse e Cizek (1994) apresentaram percentuais médios de contaminação por salmonelas da ordem de $20 \%, 13,3 \%$ e $35,5 \%$, respectivamente. Carcaças de frango obtidas em abatedouros inspecionados no Canadá e em Portugal, no período de 1986 a 1987, apresentaram percentuais de $60,9 \%$ e $57 \%$ respectivamente, e os sorovares de maior freqüência foram $S$. Heidelberg, $S$. Hadar, S. Typhimurium, $S$. Enteritidis e $S$. Agona (Lammerding et al., 1988, Machado e Bernardo, 1990).

A ocorrência de salmonelas em cortes de frango obtidos no comércio tem sido relatada por vários pesquisadores. Bokanyl Jr et al. (1990) verificaram que $43 \%$ dos cortes de frango (coxa, peito e asa) obtidos em mercados varejistas dos Estados Unidos, estavam contaminadas por salmonelas eArumugaswamy et al. (1995), na Malásia, verificaram que $39 \%$ dos cortes eram positivos para essa bactéria.

O presente trabalho teve como objetivo verificar o percentual de ocorrência de salmonelas em carcaças de frango, adquiridas em abatedouros, com e sem controle higiênico-sanitário, e em cortes obtidos no comércio, além de identificar sorovares de Salmonella nas amostras analisadas e verificar suas implicações na Saúde Pública.

\section{Material e Métodos}

Foram analisadas 150 amostras de frangos, representadas por 60 carcaças colhidas em um abatedouro com controle higiênico-sanitário permanente, 45 carcaças coIhidas em abatedouro não submetido ao citado controle e 45 amostras de cortes obtidas no comércio: 15 pares de

\footnotetext{
Apoio financeiro CAPES, Coordenadoria de Aperfeiçoamento de Pessoal de Nivel Superior

1 Pós-Graduanda do Curso de Medicina Veterinária, Área de Concentração Medicina Veterinária Preventiva, FCAVJ- UNESP

2 Departamento de Medicina Veterinária Preventiva, FCAVJ, UNESP, Rodovia Carlos Tonanni km 5, 14870-000 Jaboticabal, SP, Brasil

${ }^{3}$ Seção de Enterobactérias, Instituto Adolfo Lutz, São Paulo, SP, Brasil
} 
asas, 15 de peitos e 15 de coxas com sobrecoxas.

As carcaças foram colhidas na linha de produção, em dias normais de abate, no momento da embalagem para consumo, quando foram colocadas em sacos de polietileno esterilizados. Utilizando a técnica da "enxaguadura" (Sharf, 1972; Cox et al., 1978), adicionavam-se a cada saco 300 $\mathrm{ml}$ de água peptonada a $0,1 \%$ tamponada; todo o conjunto foi agitado vigorosamente por $1 \mathrm{~min}$. Após a "enxaguadura", a solução resultante foi vertida para frascos tipo Erlenmeyer que foram transportados ao laboratório em caixas isotérmicas contendo cubos de gelo, para manter uma temperatura uniforme em todo o material.

As amostras de cortes foram adquiridas em casas de carne, açougues e supermercados da cidade de Jaboticabal, Estado de São Paulo e transportadas ao laboratório na embalagem comum de venda ao consumidor. No laboratório, cada amostra foi transferida para um saco de polietileno e nesse se realizava o processo de "enxaguadura", utilizando $100 \mathrm{ml}$ de água peptonada a $0,1 \%$ tamponada. Nos dois casos o isolamento da salmonela iniciava-se a partir das soluções de enxaguadura.

Para isolamento das cepas de Salmonellafoi utilizada a metodologia recomendada pelo International Committee on Microbiological Specification for Food (1978) com algumas modificações. Foram utilizadas as soluções resultantes do processo de enxaguadura das carcaças e dos cortes que no laboratório eram mantidos a temperatura ambiente por $6 \mathrm{~h}$ e depois incubadas a $43^{\circ} \mathrm{C}$ por $18 \mathrm{~h}$. De cada cultura foram transferidas, de forma asséptica, alíquotas de $2 \mathrm{ml}$ para dois tubos contendo $20 \mathrm{ml}$ de caldo selenito-cistina e para outros dois tubos contendo $20 \mathrm{ml}$ de caldo Rappaport-Vassiliadis, adicionados com 0,2 $\mathrm{ml}$ de uma solução de novobiocina a 0,4\%, resultando em uma concentração de $40 \mu \mathrm{g} / \mathrm{l}$ (Pessoa e Silva, 1972). Em seguida, um tubo de cada caldo seletivo foi incubado a $37^{\circ} \mathrm{C}$ e o outro a $43^{\circ} \mathrm{C}$ por $24 \mathrm{~h}$.

Dos caldos seletivos, foram semeadas alíquotas, por esgotamento, em duas placas, uma contendo o ágar MacConkey e outra o ágar verde brilhante, e incubadas a $37^{\circ} \mathrm{C}$ por $24 \mathrm{~h}$.
A partir do plaqueamento seletivo foram tomadas, de cada uma das placas semeadas, três a cinco unidades formadoras de colônias (UFC) com características sugestivas do gênero Salmonella e inoculadas com agulha de platina em tubos contendo meio I.A.L (Instituto Adolfo Lutz) que foram incubados a $37^{\circ} \mathrm{C}$ por $24 \mathrm{~h}$ (Pessoa e Silva, 1972). Após a incubação, foi realizada a leitura, sendo presumíveis de conter salmonela as culturas que apresentavam bactérias Gram-negativas, móveis, com resultados positivos nas provas da lisina, glicose, gás e $\mathrm{H}_{2} \mathrm{~S}$ e negativas para sacarose, uréia, L-triptofano (LTD) e indol. A confirmação do gênero foi realizada por testes sorológicos com soros polivalentes anti-salmonela somático e flagelar. A sorotipagem foi realizada na Seção de Enterobactérias do Instituto Adolfo Lutz em São Paulo.

\section{Resultados e Discussão}

Pelos resultados apresentados na Tabela 1, observase que do total de 105 amostras de carcaças de frango analisadas, $11(10,5 \%)$ estavam contaminadas por salmonela. Das 60 amostras obtidas em abatedouro com controle higiênico-sanitário permanente, $5(8,3 \%)$ foram positivas; nas três primeiras colheitas não foi isolada salmonela, e nas 15 amostras analisadas na última coIheita, $5(33,3 \%)$ estavam contaminadas. No abatedouro sem controle (Tabela 1), das 45 amostras de carcaças analisadas, $6(13,3 \%)$ foram positivas para salmonela; nas duas primeiras colheitas $30 \%$ das amostras de cada uma delas estavam contaminadas, enquanto que nas duas últimas colheitas não foi isolada salmonela. O fato de não se isolar Salmonella sp. em todas as colheitas, sugere que alguns lotes de frangos, que são provenientes de diferentes locais, chegam nos abatedouros infectados pela bactéria e podem disseminá-la para as carcaças durante as fases do processamento.

A Tabela 1 revela ainda um percentual pouco maior de amostras contaminadas no abatedouro sem controle higiênico-sanitário, da ordem de $13,3 \%$, enquanto que no submetido ao controle o índice de contaminação foi de 8,3\%. Muito embora, a diferença verificada tenha sido relativa-

Tabela 1 - Percentual de isolamento de Salmonella sp. em carcaças de frango, obtidas na indústria de Jaboticabal, Estado de São Paulo, 1996

\begin{tabular}{|c|c|c|c|c|c|c|}
\hline \multirow[t]{2}{*}{ Colheita } & \multicolumn{2}{|c|}{$\begin{array}{c}\text { Abatedouro } A^{*} \\
\text { Número de amostras }\end{array}$} & \multicolumn{2}{|c|}{$\begin{array}{c}\text { Abatedouro } B^{\star \star} \\
\text { Número de amostras }\end{array}$} & \multicolumn{2}{|c|}{ Total de amostras } \\
\hline & Analisadas & Positivas & Analisadas & Positivas & Analisadas & Positivas \\
\hline 1 & 15 & $0(0 \%)$ & 10 & $3(30 \%)$ & 25 & $3(12 \%)$ \\
\hline 2 & 15 & $0(0 \%)$ & 10 & $3(30 \%)$ & 25 & $3(12 \%)$ \\
\hline 3 & 15 & $0(0 \%)$ & 10 & $0(0 \%)$ & 25 & $0(0 \%)$ \\
\hline 4 & 15 & $5(33,3 \%)$ & 15 & $0(0 \%)$ & 30 & $5(16,6 \%)$ \\
\hline Total & 60 & $5(8,3 \%)$ & 45 & $6(13,3 \%)$ & 105 & $11(10,5 \%)$ \\
\hline
\end{tabular}

abatedouro com controle higiênico-sanitário permanente; ${ }^{\star \star}$ : abatedouro sem controle 
mente pequena, esses achados mostram a importância do controle higiênico-sanitário e do serviço de inspeção médico-veterinário permanente, para que a produção de alimentos de origem animal seja de melhor qualidade.

Os resultados individualizados, obtidos em cada um dos abatedouros, mostraram percentuais de isolamento menores quando comparados com os resultados de outros pesquisadores como Machado e Bernardo (1990) que ao analisarem carcaças de frango obtidas em abatedouros portugueses verificaram que $57 \%$ das carcaças estavam contaminadas por salmonelas e Lammerding et al. (1988) que verificaram que $60,9 \%$ das amostras de carcaças obtidas em abatedouros no Canadá eram positivas. Entretanto, apesar dos percentuais encontrados neste trabalho serem menores que aqueles verificados pelos pesquisadores acima referenciados, não significa, necessariamente, que o nível de contaminação dos alimentos, principalmente dos produtos cárneos, tenha diminuído ou esteja controlado.

A Tabela 2 apresenta o percentual de isolamento de Salmonella sp. a partir de amostras de cortes de frango obtidas no comércio. Pelos dados verifica-se que das 45 amostras analisadas, 16 (35\%) estavam contaminadas por salmonela. Desse total, 15 eram de asas, onde se isolou salmonela em $46,6 \%$ delas, 15 de coxas, detectando-se salmonela em $20 \%$ e as 15 restantes de peito onde $40 \%$ foram positivas para salmonelas. Os percentuais de contaminação foram semelhantes aos de outros pesquisadores como Bokanyl Jr et al. (1990) que ao analisarem cortes de frango verificaram que $43 \%$ das amostras estavam contaminadas e de Arumugaswamy et al. (1995) que verificaram que $39 \%$ dos cortes adquiridos no mercado varejista da Malásia eram positivos para salmonelas.

Comparando os achados da Tabela $2 \mathrm{com}$ aqueles apresentados na Tabela 1 verifica-se que o percentual de contaminação das carcaças obtidas nos abatedouros, de $10,5 \%$, é menor que o verificado nos cortes obtidos no comércio, $35 \%$. Essa diferença talvez possa ser atribuída a uma maior manipulação dos cortes, condições de higiene e temperatura de armazenamento, nem sempre adequadas ao nível de comércio.

Pelos dados apresentados na Tabela 3 verifica-se que do total de 150 amostras de frango analisadas, foram iden-

Tabela 2 - Percentual de isolamento de Salmonella sp. em cortes de frango, obtidos no comércio de Jaboticabal, Estado de São Paulo, 1996

\begin{tabular}{lcc}
\hline & \multicolumn{2}{c}{ Total de amostras } \\
\cline { 2 - 3 } Amostras de cortes & Analisadas & Positivas \\
\hline Asas & 15 & $7(46,6 \%)$ \\
Coxas & 15 & $3(20 \%)$ \\
Peitos & 15 & $6(40 \%)$ \\
\hline Total & 45 & $16(35 \%)$ \\
\hline
\end{tabular}

tificados dez diferentes sorovares, sendo três de carcaças (S. Senftenberg, S. Schwarzengrund e S. Minnesota) e sete de cortes, (S. I 4,5,12,:r:-, S. Heidelberg, S. Anatum, S. Hadar, S. Enteritidis, S. Agona e S. I 1,4,5,12:r:-). O sorovar predominante foi a $S$. Enteritidis. Alguns dos sorovares identificados neste estudo foram também evidenciados por outros pesquisadores como Cunha Neto et al. (1982) que isolaram os sorotipos $S$. Anatum e $S$. Typhimurium, Lammerding et al. (1988) que isolaram os sorovares $S$. Heidelberg, $S$. Hadar e $S$. Typhimurium e Machado e Bernardo (1990) que isolaram S. Agona e S. Enteritidis de carcaças obtidas em abatedouros. Bokanyl Jr et al. (1990) identificaram S. Hadar e S. Heidelberg e Arumugaswamy et al. (1995) isolaram S. Enteritidis de cortes de frango obtidos no mercado verejista.

Tabela 3 - Sorovares de Salmonella isolados de carcaças e cortes de frango, obtidos na indústria e no comércio de Jaboticabal, Estado de São Paulo, 1996

\begin{tabular}{lclc}
\hline Amostras & Número & Sorovares identificados & $\begin{array}{c}\text { Número de } \\
\text { cepas }\end{array}$ \\
\hline Carcaças & $105 / 11^{*}$ & Salmonella Senftenberg & 11 \\
& & Salmonella Schwarzengrund & 15 \\
Coxas & \multirow{2}{*}{$15 / 3$} & Salmonella Minnesota & 8 \\
& & Salmonella I 4,5,12: r:- & 3 \\
& & Salmonella Heidelberg & 3 \\
& & Salmonella Anatum & 4 \\
Peitos & \multirow{2}{*}{$15 / 6$} & Salmonella Hadar & 2 \\
& & Salmonella Enteritidis & 3 \\
& & Salmonella I 1,4,5,12:r:- & 1 \\
Asas & & Salmonella Hadar & 1 \\
& \multirow{2}{*}{$15 / 7$} & Salmonella Agona & 4 \\
& & Salmonella Enteritidis & 22 \\
Total & $150 / 27$ & Salmonella Hadar & 10 \\
\end{tabular}

${ }^{\star}:$ total de amostras analisadas/total de amostras positivas

Ainda com relação aos sorovares identificados no presente estudo, pode-se afirmar que todos podem ser considerados como agentes de toxinfeção em potencial, em particular os sorovares $S$. Anatum e $S$. Enteritidis. A esse respeito podem ser citados os trabalhos de Taunay (1968) que fazendo um estudo retrospectivo de 17 anos, com dados colhidos junto ao Instituto Adolfo Lutz, São Paulo, verificou que as salmonelas de origem animal foram responsáveis por $9,8 \%$ das gastroenterites agudas em crianças e que os sorovares mais freqüentes foram $S$. Newport, $S$. Anatum, S. Typhimurium e S. Derby e o de Coggo et al. (1994) que no México, no período de 1982 a 1993, verificaram como predominantes, em amostras clínicas, os sorovares $S$. Typhimurium, $S$. Enteritidis e $S$. Typhi. 


\section{Conclusões}

Nas condições em que o trabalho foi realizado e com base no número de amostras analisadas e nos resultados obtidos foi possível concluir que (1) embora o percentual de contaminação verificado nas carcaças obtidas no abatedouro com controle higiênico-sanitário não apresente uma grande diferença em relação ao nível de contaminação verificado nas carcaças do abatedouro sem controle, admite-se que o controle higiênico-sanitário permanente, quando realizado na indústria avícola, contribui para reduzir os níveis de contaminação dos produtos por salmonela; (2) o percentual de carcaças contaminadas por salmonela foi menor que o de cortes; (3) a $S$. Enteritidis foi o sorovar predominante.

\section{Agradecimentos}

À FCAVJ/UNESP e ao Instituto Adolfo Lutz, São Paulo.

\section{Abstract}

\section{Serovars of Salmonella isolated from carcass and cuts of chicken obtained from industry and commerce, in Jaboticabal, State of São Paulo, during 1996}

In order to verify the occurrence of Salmonellasp. and identify its serovars, 105 chicken carcasses samples obtained from slaughterhouse (60 from stablishments controlled hygienically and 45 without control) as well as from commercial cuts (breast, thigh, and wing) at the retail taken market of Jaboticabal city, State of São Paulo, were analyzed. In the samples from the controlled slaughterhouse, $8.3 \%$ of the carcasses were positive for salmonela whereas in those without control were $13.3 \%$. In the cuts contamination mean percentual for Salmonella was $35 \%$, being $46.6 \%$ of wings samples, $40 \%$ of breast and $20 \%$ of thigh. Ten different serovars were identified: $S$. Senftenberg, $S$. Schwarzengrund, S. Minnesota, S. I 4,5,12:r:-, S. Heidelberg, S. Anatum, S. Hadar, S. Enteritidis, S. Agona e S. I $1,4,5,12: r:-$, being $S$. Enteritidis the most frequent. Strict hygienical measures must be taken concerning production, slaughterhouse and commerce to reduce the percentage of carcasses and chicken cuts contamination and therefore the risks to the Public Health.
Key words: Salmonella sp.; chicken meat; slaughterhouse; market

\section{Referências bibliográficas}

Arumugaswamy RK, Rusul G, Abdul Hamid SN, Cheah CT 1995. Prevalence of Salmonella in raw and cooked foods in Malaysia. Food Microbiol 12(1): 3-8.

Bokanyl Jr RP, Stephens JF, Foster DN 1990. Isolation and characterization of Salmonella from broiler carcasses or parts. Poult Sci 69: 592-598.

Coggo LG, Bonilla CG, Cerezo SG, Beltran LG 1994. Principales sorotipos de Salmonella identificados en 10.703 cepas en México entre 1982 y 1993. Ver Latino Am Microbiol 36: 221-226.

Cox NA, Mercuri AJ, Tanner DA, Carson MO, Thomson JE, Bailey JS 1978. Effectiveness of sampling methods for Salmonella detection on processed broilers. J Food Protect 41: 341-343.

Cunha Neto SJ, Brant PC, Pessoa GVA 1982. Sorotipos de salmonela isolados de concentrado, cama e carcaças de frangos de corte em duas granjas em Goiânia, GO, 1974. Arq Bras Med Vet Zootec 34(2): 337-344.

International Committee on Microbiological Specification for Food 1978. Microrganisms in food. I - Their significance and methods of enumeration. 2.ed., University Press, Toronto, $434 \mathrm{pp}$.

Lammerding AM, Garcia MM, Mann ED, Robinson Y, Dorward WJ, Truscott RB, Tittiger F 1988. Prevalence of Salmonella and thermophilic Campylobacter in fresh pork, beef, veal and poultry in Canada. $J$ Food Protect 51(1): 47-52.

Machado J, Bernardo F 1990. Prevalence of Salmonella in chicken carcasses in Portugal. J Appl Bacteriol 69: 477-480.

Machado RA, Tosin I, Leitão MFF 1994. Occorrence of Salmonella sp. and Campylobacter sp. in chickens during industrial processing. Ver Microbiol 25(4): 239-244.

Pessoa GVA, Silva CAM 1972. Meios de Rugai e lisina-motilidade combinados em um só tubo para identificação presuntiva de enterobactérias. Rev Inst Adolfo Lutz 32: 97-100.

Sharf JM 1972. Exame microbiológico de alimentos. Polígono, São Paulo, $257 \mathrm{pp}$.

Tadesse WM, Cizer A 1994. The isolation of Salmonella from poultry carcasses and equipments in the poultry processing plant by means of two procedures. Vet Med 39(6): 315-320.

Taunay AE 1968. Diagnóstico bacteriológico das salmonelas de origem animal, sua importância e freqüência no município de São Paulo. Ver Inst Adolfo Lutz 28: 43-69. 